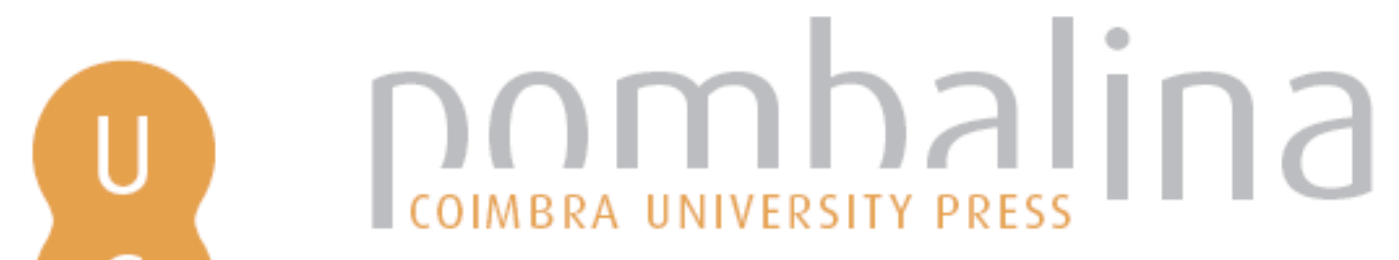

\title{
A ilha dos amores e o imaginário da utopia
}

\author{
Autor(es): Rebelo, Luís de Sousa
}

Publicado por: Imprensa da Universidade de Coimbra

URL

persistente: URI:http://hdl.handle.net/10316.2/30743

DOI: DOI:http://dx.doi.org/10.14195/978-989-26-0569-2_5

Accessed : $\quad$ 26-Apr-2023 03:33:42

A navegação consulta e descarregamento dos títulos inseridos nas Bibliotecas Digitais UC Digitalis, UC Pombalina e UC Impactum, pressupõem a aceitação plena e sem reservas dos Termos e Condições de Uso destas Bibliotecas Digitais, disponíveis em https://digitalis.uc.pt/pt-pt/termos.

Conforme exposto nos referidos Termos e Condições de Uso, o descarregamento de títulos de acesso restrito requer uma licença válida de autorização devendo o utilizador aceder ao(s) documento(s) a partir de um endereço de IP da instituição detentora da supramencionada licença.

Ao utilizador é apenas permitido o descarregamento para uso pessoal, pelo que o emprego do(s) título(s) descarregado(s) para outro fim, designadamente comercial, carece de autorização do respetivo autor ou editor da obra.

Na medida em que todas as obras da UC Digitalis se encontram protegidas pelo Código do Direito de Autor e Direitos Conexos e demais legislação aplicável, toda a cópia, parcial ou total, deste documento, nos casos em que é legalmente admitida, deverá conter ou fazer-se acompanhar por este aviso.

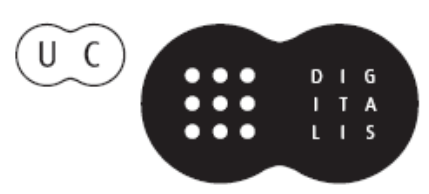




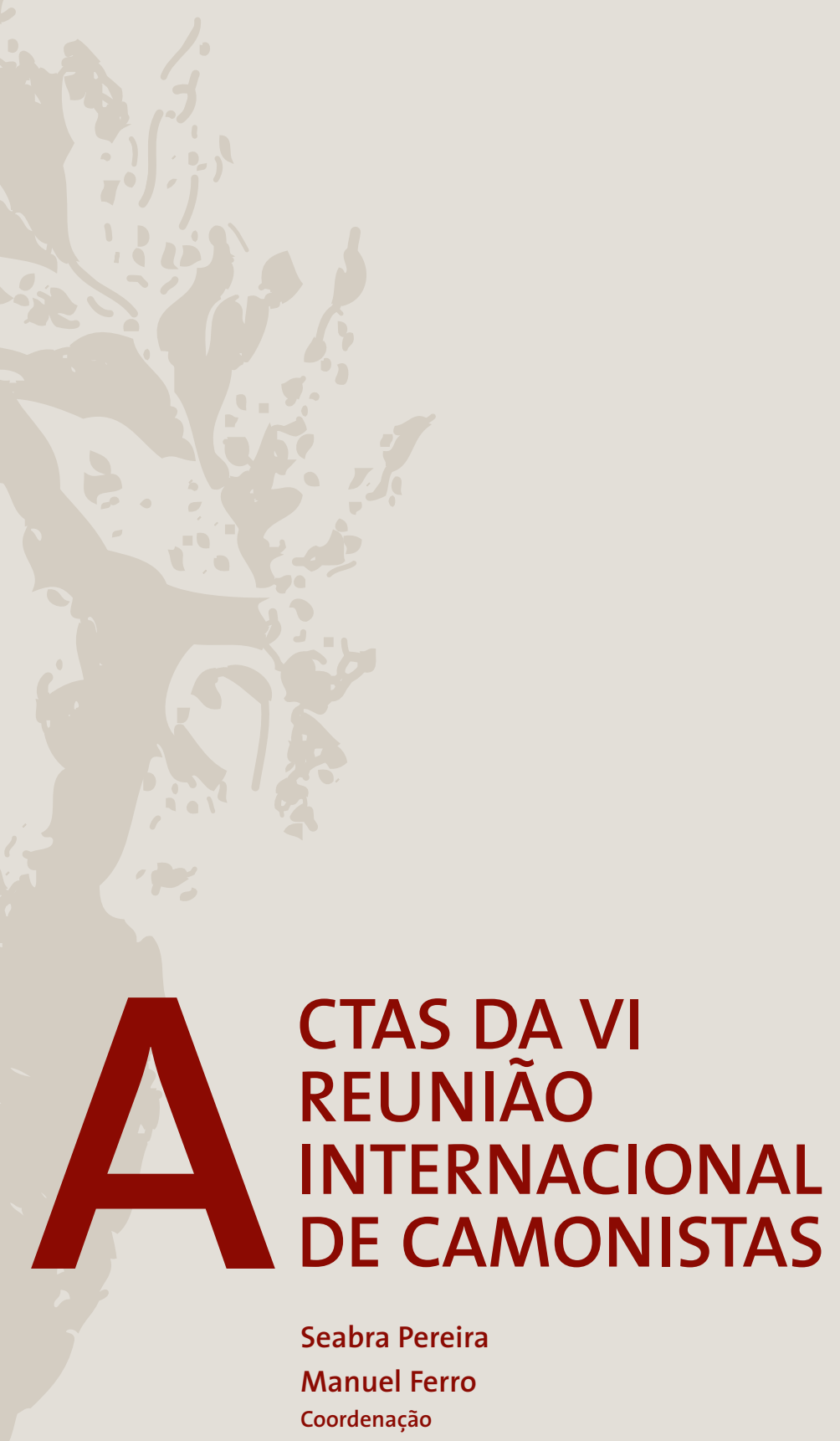




\section{Luís de Sousa Rebelo}

Universidade de Lisboa

\section{A ILHA DOS AMORES E O IMAGINÁRIO DA UTOPIA}

Agora que o fim do milénio se aproxima e o exame do curto século vinte, que vai de 1914 a 1991, permite compreender o sentido do seu processo histórico, importa sondar, na medida do possível, os efeitos que este terá tido nos modos de recepção da obra dos grandes clássicos. A inquietude e certo nervosismo de que dão prova nos seus escritos conhecidos mentores da opinião pública e analistas da cena literária contemporânea trazem precisamente o receio de uma erosão de valores que se estenda aos cânones estéticos da cultura ocidental.

Entre as grandes transformaçóes, que se deram neste último quartel do século, a dissolução dos velhos impérios e o surto dos novos estados das ruínas da ordem anterior, estados cujas dores de crescimento ainda não terminaram, suscita no leitor, ou em certos grupos de leitores, a hostilidade a uma temática de glorificaçáo imperial. O patriotismo, que com ela se associa, torna-se ofensivo para aqueles que ressentem a perspectiva em que se situa a história dos seus antepassados. Como poderá ler $O s$ Lusiadas um leitor que nele não se reconheça como seu destinatário, nem se identifique com a história do povo a que pertencem os "varóes assinalados»? As suas convicçóes ideológicas levam-no a resistir à mensagem que a obra lhe transmite e a repudiá-la na sua complexidade. Um tipo de resposta é fazer uma anti-leitura do poema: produzir um texto que rompa a forma do discurso épico e mude os seus códigos de expressão. O que precisamente se nos depara n’As Quybyricas, poema de António Quadros publicado em Moçambique, ou mais exactamente na Lourenço Marques de entáo, em Novembro de 1972. A própria escolha do signo trágico de Alcácer Quibir denota a intenção anti-épica do poema, que se classifica (repare-se bem) de "poema em outavas», cujo autor se oculta sob um pseudónimo, procurando, assim, a invisibilidade dos antiheróis, as anónimas figuras com as quais se identifica ${ }^{1}$. Escrito num tom paródico, o poema mostra o reverso do ideal do império e as consequências de um patriotismo de vocação expansionista, sem que, por isso mesmo, deixe de ser uma homenagem prestada ao cantor d'Os Lusiadas.

${ }^{1}$ Publicado sob o pseudónimo de João Pedro Gravato Dias, António Quadros (1923-1994) era um grande pintor. Natural de Viseu, viveu bastantes anos em Moçambique, tendo-se identificado com a vida cultural desse país. 
A Europa do Renascimento soube conciliar com arte ideias e princípios que só na aparência eram contraditórios, fazendo dessa concordância ou conjugação o discurso da sua própria modernidade. Ao cosmopolitismo trazido pelos humanistas, que abre fronteiras e procura criar a tolerância, junta, nos escritos dos portugueses e de outros autores, a progressiva afirmação do sentimento nacional, que diferencia as diversas comunidades e as distingue na sua originalidade ética e cultural.

De Petrarca a Camôes o sentimento patriótico é o mesmo. Na canção "Italia mia", Petrarca celebra «il mio nido / ove nudrito fui si dolcemente». Camóes n'Os Lusíadas, utilizando a mesma metáfora, canta "o ninho meu paterno" (I.10) e "a ditosa pátria minha amada» (III.21) ${ }^{2}$. Sobre o ocaso do século, ou mais rigorosamente em 1597, Shakespeare, no Ricardo II, manifesta idêntico ardor patriótico. John de Gaunt, duque de Lencastre, uma das suas "dramatis personae", como se sobre ele subitamente houvesse descido uma língua de fogo divino, oferece-nos da Inglaterra uma visão profética. Num belíssimo passo, traça-nos o quadro de uma ilha afortunada, bafejada por todos os dons da Natureza, "um outro Eden, um semi-paraiso", onde a concórdia e a paz poderiam reinar perpetuamente, não fosse a incapacidade das gentes que a habitam para se governarem e domarem o ódio que as divide. Conclui a sua meditação com um juízo, que tem a qualidade de um epifonema camoniano: "a Inglaterra afeita a conquistar os outros / De si mesma fez uma vergonhosa conquista”:

"That England, that was wont to conquer others,

Hath made a shameful conquest of itself." 3

Compreende esta conquista tanto o sentido da sujeição do outro - incluindo as ambiçôes da sucessão - quanto o domínio das paixóes do próprio eu. A resipiscência ou arrependimento dos actos cometidos, a consciência das debilidades do género humano na construção do seu próprio destino, são inseparáveis da consciência da história, e delas nos dá o Renascimento um constante testemunho. A conquista faz parte da cultura política de Portugal, Espanha e Itália, onde uma imaginativa concepção do império a integrava como um factor operativo. Em Camóes tem o valor de cruzada, quando se refere à luta com o Islão (VII.2), e é reconhecida como indevida quando se reporta ao território dos Leoneses, tomado por D. Afonso Henriques (III.70). As hostilidades que, ao longo do processo de expansão, se mantêm com os povos islâmicos, pretendem continuar as que se iniciaram na Península Ibérica. Para a Europa de Quinhentos, que vivia sob a ameaça do poder otomano, Portugal surgia, ao lado de Castela, como um dos estados cristãos, senáo o primeiro, a romper esse cerco, ou como tal considerado, se tivermos em conta que o descobrimento do caminho marítimo para a Índia o levava a regióes que se encontravam sob a influência muçulmana.

Neste contexto figuram as palavras, os sintagmas, os passos que um certo leitor d'Os Lusíadas, ou um determinado grupo de leitores, tem como ofensivo para a dignidade dos povos com quem os Portugueses se depararam. Além de conquista e seus correlatos, sintagmas como 'fé e império', ou referências ao "torpo ismaelita”, contêm uma carga emotiva que faz deles termos de objecçáo / abjecção na leitura do poema.

\footnotetext{
${ }^{2}$ É a canção n. ${ }^{\circ}$ CXXVII de Petrarca. Ver Luís de Sousa Rebelo, "Camóes e o sentido de comunidade", Camóes e o Pensamento Filosófico do seu Tempo, 1979, pp. 61-94.

3 William Shakespeare, Richard II, Acto II, vv. 65-66.
} 
À luz de uma crítica que ignora a história das mentalidades e o que ela representa na formação da sensibilidade estética, os passos apontados constituem em si mesmos motivo suficiente para que a obra seja desestimada na sua totalidade, já que ela se revela obsoleta e inadequada às aspiraçóes do futuro, como se pressente nas reacçóes que desperta neste fim do milénio.

Não é esta, aliás, a primeira vez que se põe o problema. António José Saraiva já se referiu à violência de expressão a que recorre o poeta quando descreve a acção militar dos Portugueses. Ela anuncia-se na proposição. Camóes vai cantar as memórias gloriosas daqueles que foram dilatando "a fé, o Império e as terras viciosas / De África $e$ de Ásia andaram devastando» (I.2). Não há palavra mais dura na língua portuguesa do que "devastar" e a referência às "terras viciosas", as terras do infiel, tem um valor depreciativo muito pesado. O discurso da conquista e da implantaçáo lusitana em terras de além-mar conflui e compagina-se com o discurso do descobrimento das rotas marítimas e do contacto com o Outro, discurso este que ocupa efectivamente a parte principal do poema, fornecendo-lhe o fio narrativo. A luta que se trava na terra e no Índico nasce da oposição aos novos concorrentes comerciais. "Quem não quer comércio, busca guerra» (VIII.92), diz o poeta, e este é o argumento que justifica a natureza dos conflitos. Quando a Ninfa, no canto X (estrofe 10), vaticina o que se seguirá à abertura do caminho marítimo para a Índia, ela expóe sem ambages uma via de conquista imperial, que será imposta pelas armadas vindas de Lisboa:

"E que os gentios reis que não dariam

A cerviz sua o jugo, o ferro e ira

Provariam do braço duro e forte,

Até render-se a ele e logo à morte." ${ }^{4}$

Tethys, que substitui a Ninfa na descrição profética das façanhas lusíadas cometidas no orbe terrestre, assume, no seu relato, a superioridade civilizacional da Europa sobre o continente africano. "Vês», diz ela ao Gama, "África, dos bens do mundo avara, / Inculta e toda cheia de bruteza» (X.92) e traça de seguida um quadro de incompreendida realidade antropológica. Os nomes, os epítetos e os sintagmas utilizados na pintura dos povos orientais e dos africanos vêm assinalados com a marca da submissão - «dar a cerviz ao jugo» - e os africanos são caracterizados pela bruteza do seu modo de vida, quando comparado com o europeu: "gente selvática, negra e nua» (X.93), gente inculta e bruta. Trai a apresentação destas vinhetas e surpresa da descoberta do Outro, ao notar-lhe a diferença que o distingue, seja a nudez, seja a confiança de uma comunidade africana que habita casas sem portas (X.139). A observação respectiva muda, chega, porém, quase a objectivar-se, quando Tethys descreve o Novo Mundo. Além de uma breve referência ao ouro que adornou «o rudo colo» e do qual Castela se apropriou (X.139), o Brasil, a terra de Vera Cruz, é apresentado sem qualquer qualificativo menos honroso para as suas gentes.

Por outro lado, falar de incompreendida realidade antropológica constitui um anacronismo em relação à mentalidade da Europa quinhentista. $\mathrm{O}$ africano era para o

\footnotetext{
${ }^{4}$ Luís de Camões, Os Lusíadas, ed. organizada por Álvaro Júlio da Costa Pimpão, Lisboa, 1972.
} 
europeu um ser que vivia em conformidade com as leis da natureza. A "feritas" opunhase à "civilitas", criação artificial e invençáo dos homens, a sociedade organizada com uma ordem hierárquica, um rei, magistrados e o sentido da justiça e da vida política. Ignorar estas mediaçóes culturais é correr o risco de não compreender o poema. Nem elas escondem que a mundividência camoniana era a de um católico monárquico, consciente da importância dos descobrimentos e do império, que terá de se manter, sempre que necessário seja, pela força das armas.

Mas as convicçôes do homem e do cidadão não são aceites sem conflito no seu foro íntimo, nem constituem uma adesáo de princípio que náo esteja sujeita ao exame do que nela haja ou possa haver de contraditório. Camóes situa-se numa charneira que divide o antigo do moderno, entre um pensamento medieval e um pensamento moderno, que pouco a pouco se afirma e o obriga a meditar sobre a experiência vivida. Pronuncia-se amiúdas vezes sobre o sentido e os efeitos do poder, sobre os seus limites, sobre os excessos dos chefes militares, sobre a ingratidáo dos reis para aqueles que melhor os servem. Estas suas intervençôes no poema, a voz do autor, que é simultaneamente a voz do actor que vive no seu agora a experiência do outrora, constituem um rasgo original, notado, entre outros, por Roger Bismut.

A frequência dessas intervençóes é superior n'Os Lusiadas à que se encontra nas epopeias que o precederam, atingindo, segundo o cômputo estabelecido por aquele estudioso, quarenta por cento da totalidade do poema 5 . Poema de reflexão ética individual e política, ele é também o espelho dos preconceitos do século e da época no qual se projecta o conflito da própria consciência de Humanidade, onde as diferenças entre os homens se diluem com as suas paixôes e particularismos. O Professor Martim de Albuquerque, primeiro que foi a observar o emprego dos vocábulos 'humanidade e humano' n'Os Lusiadas, reconhece entre eles uma conexão dialéctica que opóe as ideias de grandeza e fraqueza ${ }^{6}$. Uma digna de exaltação, a outra de censura. Neste enquadramento, o patriotismo afigura-se uma tentativa de sublimaçáo do humano mediante a conquista da glória. As violências de comportamento, certas práticas que se revelam na conduta humana, qual é o canibalismo (X.126), certos excessos que derrogam ao sentido de humanidade - «Se de humano é matar uma donzela» (III, 127), no caso de Inês de Castro -, todas estas facetas que a memória e as peregrinaçôes do poeta pelo mundo lhe vão revelando, constituem no seu conjunto a caracterização da condição humana, aquela mesma que, numa visão etérea da realidade, ele define como «o baixo trato humano embaraçado» (V.99).

Para além da ufania que lhe inspira o processo dos descobrimentos, Camóes revelase, com todas as debilidades e preconceitos inerentes à condição humana, como o poeta dessa mesma condição. A compreensão que desta tem provém-lhe da sua mesma concepção de humanidade, da humanitas. Palavra que, segundo Aulo Gélio, representa o trabalho do espírito e da natureza modelados pela cultura e pela educação - fenómeno único no reino animal e exclusivo da nossa espécie.

\footnotetext{
${ }^{5}$ Roger Bismut, "Contribution à un centenaire: une tentative de rénovation épique, Les lusiades de L. Camôes”, separata, Lisboa, 1972, p. 26.

${ }^{6}$ Martim de Albuquerque no discurso de agradecimento pela atribuição do Prémio de Investigação D. João de Castro, Oceanos, no 4, Julho 1990, pp. 20-22.
} 
A humanitas implica consequentemente todo o complexo processo da paideia. Por isso Os Lusíadas - fruto do honesto estudo - tanto tem de aprendizado e experiência. A aprendizagem dos trabalhos do mar e da navegação. Aprendizagem do modo de olhar, de observar usos e costumes de povos tão diversos. Aprendizagem administrativa e da acção diplomática. Aprendizado e experiência do Amor a que o exílio traz novas e doridas tonalidades. Experiência da morte e da vida. O próprio poema épico, na longa recensão histórica que ocupa uma larga parte da narrativa, propóe uma meditação sobre o destino de Portugal, que tem como fonte a história aprendida / apreendida nas crónicas do reino.

O discurso d'Os Lusiadas vem animado, porém, por uma veemente aspiração ética, pelo desejo da arte de bem governar, embora esse desejo apareça toldado pela melancolia que lhe imprime o trato com a retorcida natureza humana. A experiência individual do poeta exprime-se dentro do quadro da memória colectiva que serve a elaboração da epopeia. É bem conhecido o horizonte de espera que ela veio satisfazer. Mostra-o, se mais fosse necessário, a epístola de Erasmo, redigida em Basileia e dirigida em 1527 a D. João III. Depois de louvar os feitos de uma pequena nação, que se equipara a Esparta no tamanho e na gesta heróica, aponta o humanista os efeitos do monopólio comercial exercido pela Coroa, dela esperando remédio para esses males. O paralelo com Esparta mais do que um rasgo de retórica, constitui um incentivo a um ideal político a que Portugal deveria visar.

Para certos leitores, a historicidade do poema constitui uma das suas dificuldades. Resistência esta que não é recente, mas vem desde as primeiras décadas do século. O poeta Ezra Pound, em The Spirit of Romance (1910), punha sérias restriçóes ao prestígio literário d'Os Lusíadas e à sua perdurabilidade como cânone estético. Mau grado observaçóes que traem uma leitura menos atenta ou precipitada, quando afirma, por exemplo, que Camóes era capaz de escrever uma epopeia em dez cantos sem fazer uma pausa, uma vez sequer, para emitir uma reflexão de cariz filosófico. Ezra Pound reconhecia no poema um encanto que provinha da firme crença do seu autor na glória das exterioridades: "his firm belief in the glory of externals» ${ }^{7}$. Por outro lado, apontavalhe como a sua maior franqueza, o ser o poema épico de um grupo, o segmento de um povo e não a sua humanidade.

À luz das consideraçôes precedentes, estas leituras revelam-se, em parte, como leviandades ou equívocos, como o resultado de uma visão literária desarmada, que voluntariamente prescindiu do aparelho cultural que se aplica ao estudo de uma obra do passado. O próprio facto do género épico ter atingido, depois de Milton, a sua absolescência, contribui decerto, por outra parte, para um deslocamento da empatia do leitor, que passa a ser atraída pela ficção científica e por meios mais eficazes da comunicação pela imagem. As odisseias do nosso tempo são menos odisseias de um presente mitificado do que odisseias do futuro a que um Stanley Kubrick, entre outros, responde com maior popularidade na arte cinematográfica do que logra fazê-lo a literatura ${ }^{8}$.

Não são, porém, estas razóes, aliás impensáveis no tempo em que escrevia, que levam Ezra Pound a ser tão reservado nos seus juízos sobre Os Lusíadas. Elas partem

\footnotetext{
${ }^{7}$ Ezra Pound, The Spirit of Romance, Londres, 1970, pp. 214-222, p. 216.

${ }^{8}$ John Kevin Newman, The Classical Epic Tradition, Wisconsin, 1986.
} 
de uma convicção mais profunda. A sua apreciação da Eneida de Virgílio póe-nos de certo modo de sobreaviso. Para ele Virgílio "não tem no poema uma história que valha a pena contar, nem sentido de personalidade», rejeitando assim uma tradição que remonta às origens da criação literária como a conhecemos ${ }^{9}$. Porque é precisamente nesta que reside, para ele, o grande equívoco da literatura do Ocidente, quando optou pela mimese, por uma arte permanentemente vinculada à ideia da representação, a que alguns já na Antiguidade tinham sabido furtar-se.

Mais recentemente e já com a mira no fim do milénio, Harold Bloom enfrenta modos de leitura que se vão institucionalizando nas universidades norte-americanas e difundindo um pouco por toda a parte, os quais julgam a obra literária não segundo um critério estético mas em função de uma postura crítica que se serve dela para remediar injustiças sociais. Nesta classe de críticos e comentadores se devem incluir aqueles que, directamente ou por associação, destacam os passos d'Os Lusiadas onde se nota a diferenciação depreciativa do outro, anunciando deste modo a mortalidade da epopeia.

Ora a existência de um cânone literário, criado ao longo dos séculos, constitui um permanente desafio de escrita, onde Harold Bloom detecta uma quota parte de angústia na influência que essas obras paradigmáticas possam exercer sobre o autor. A criaçáo é de facto um fenómeno dinâmico, um conflito entre o presente e o passado, que pode alterar a ordem e as jerarquias do cânone. Em The Western Canon (1994), Bloom inclui Camóes e a sua epopeia na galáxia onde Shakespeare brilha como astro de primeira grandeza, mas prescinde de qualquer comentário sobre o poema, tomado como factor integrado. O seu interesse detém-se em Fernando Pessoa/Álvaro de Campos, cuja ligação com Walt Whitman lhe fornece a legitimidade do modelo literário. As sondagens do "eu", a despersonalização com todos os seus desdobramentos, os heterónimos, fazem de Pessoa, na expressão de Harold Bloom, um "Whitman renascido" ("Whitman reborn») e certamente um poeta bem mais próximo das aspiraçóes deste fim do milénio do que Camóes ${ }^{10}$. Tem-se esquecido que, no diálogo subtextual da Ode Marítima, se descobre um discurso épico que vem, por vezes, ao de cima e serve o desejo de transmigraçáo do "eu" para a era dos descobrimentos, para a alma desses homens de antanho que ergueram padrôes e se espalharam pelo mundo:

"Fugir convosco à civilização!

Perder convosco a noçáo da moral!

Sentir mudar-se ao longe a minha humanidade!

Beber convosco em mares do Sul

Novas selvajarias, novas balbúrdias da alma,

Novos fogos centrais no meu vulcânico espírito! ${ }^{11}$

A anulação do quotidiano, este adeus à melancolia dos dias anódinos, vem imbuída de uma consciência dos valores, do seu conflito e transformação no trabalho

\footnotetext{
${ }^{9}$ Id., Literary Essays of Ezra Pound, Londres, 1968, p. 215.

${ }^{10}$ Harold Bloom, The Western Canon, Londres, 1995, pp. 485-492.

11 Obra Poética de Fernando Pessoa, Nova Aguilar, Rio, 1986, pp. 256.
} 
da memória, que acerta com as preocupaçóes da epopeia camoniana na temática do humano e da humanidade. Curiosamente nem Ezra Pound, nem Harold Bloom (talvez devido à ausência de traduçôes fiáveis) referem jamais a obra lírica de Camóes, onde estas contradiçóes são mais intensas. Original e imaginativa é, por isso, a leitura, que, nos anos oitenta, Hélder Macedo faz d'Os Lusíadas e se encontra numa linha de continuidade traçada, entre outros, por Jorge de Sena. Examinando a natureza da viagem n'Os Lusíadas e o carácter da sua demanda, Macedo explora o que nela há de simbólico e articula a temática pessoal de Camóes, registada na lírica, com as preocupaçóes cívicas do poema. Assinala, deste modo, o percurso espiritual da viagem, "uma viagem iniciática personalizada num herói», cujo sentido se fundamenta na concepção camoniana do Amor. A sua exegese coloca Os Lusíadas no âmbito de expectativas que são consentâneas com as apetências culturais do nosso tempo e sensíveis a uma crítica psicológica atenta aos acenos do subconsciente ${ }^{12}$.

As interpretaçóes do poema, focado por diferentes prismas, a intermutabilidade das personagens e das suas vozes, a recorrente reflexão do poeta sobre o curso dos eventos, destacam a personalidade de Camóes contra a tapeçaria histórica da epopeia. Escritor e cidadão, os seus valores são também valores colectivos, e a compreensão disciplinar, que eles impóem, não deixa de calcar anseios e aspiraçóes individuais que se traduzem num conflito interior.

Entende-se a disciplina como necessária à realização de um grande empreendimento, qual foi a expansão, que teve no patriotismo a sua mola real. Mas, nem por isso, o sofrimento e as perplexidades decorrentes das contradiçóes humanas foram menos sentidas, ainda que mais visíveis sejam elas na obra lírica. Considerar Os Lusiadas um modelo estático e ideal de verdade, baseado em valores éticos quinhentistas, que propóe uma ideia de Portugal, posteriormente desmentida pelo curso da História, é optar por uma leitura política datada, que esvazia o poema do desejo de mudança e da aspiração a um superior ideal de justiça ${ }^{13}$. Isolar episódios do poema, referenciandoos ao desaparecimento material do império para mostrar a sua irrelevância, é atentar contra a unidade estética da obra. Nem tudo se deve ver por um prisma negativo. A comunicação estabelecida com os descobrimentos entre os povos do globo fica como um feito irrevogável de civilização, assinalado, aliás, com tanto maior vigor no poema quanto maior é a consciência que dele ganha «um bicho da terra tão pequeno».

Ora, se a crítica está hoje mais interessada em estudar o protagonismo de Camóes n'Os Lusíadas, verdade é que o desejo do poeta não se exprime com o amoralismo de Álvaro de Campos e a vontade de transfiguração manifesta na Ode Marítima, mas, sim, com o voto colectivo de transformação moral, que tem na "Ilha dos Amores" a sua metaforização utópica. Episódio que tem feito correr muita tinta, não pode aplicarse-lhe a designação de utopia no sentido e em conformidade com o género criado por Thomas More, como lucidamente o demonstrou Vítor Manuel Aguiar e Silva ${ }^{14}$.

12 Hélder Macedo, Camóes e a Viagem Iniciática, Lisboa, 1980.

${ }^{13}$ Cfr. Luís de Oliveira e Silva, "Identidade e identificação interactiva n’Os Lusíadas", Dedalus, n5, Lisboa, 1995, pp. 217-230.

${ }^{14}$ Vítor Manuel Aguiar e Silva, "Imaginação e pensamento utópicos no episódio da 'Ilha dos Amores”, Biblos, vol. LXIV, 1988, pp. 81-90. 
A Ilha dos Amores transporta-nos a um espaço de possibilidade futurante, dando forma a anseios que são tão antigos quanto a consciência da própria humanidade. Esta concepção da utopia, tal como foi definida por Ernst Bloch ${ }^{15}$, permite reconhecer que a 'Ilha dos Amores' não é apenas uma alegoria, mas uma utopia por direito próprio, o lugar onde culminam desejos e aspiraçôes que se encontram disseminados ao longo do poema. A 'ínsula divina' oferece uma paisagem idílica, representando o prémio, o galardão concedido aos nautas. O seu simbolismo mítico compreende o aparecimento de uma nova humanidade, como é expressamente sublinhado por Vénus. O conúbio de homens e deidades anuncia um novo ciclo na história da humanidade ao produzir uma "progénie forte e bela»; prenuncia a esperança de uma nova ordem que pusesse fim à perversão da justiça e do amor - o advento de um mundo que configurasse tanto quanto possível um ideal utópico.

No complexo simbolismo que se encontra na Ilha dos Amores acumula-se uma sedimentação semântica que nem sempre tem sido devidamente discernida e mostra a amplitude do horizonte de expectativa em que ela se enquadra. $\mathrm{O}$ episódio tem raízes numa tradição popular, que ficou de certo modo obscurecida pela sublimação que lhe imprime a narrativa épica. Com efeito, a ideia de uma ilha dos desejos, que a erudição clássica já explorou exaustivamente em torno das «ilhas dos bem-aventurados», remonta ao imaginário popular, onde ela aparece sob formas diversas. No mundo pagão é a ilha de Pomona, a ilha das maçás. Aí um palácio de cristal flutuante transporta as almas dos justos. Conhece depois outras metamorfoses. Na Espanha, França, Itália e na Inglaterra transforma-se na terra de Cucanha, descrita em certas versóes da primeira década do século XIV como superior ao próprio paraíso. Cucanha é um paraíso terreal, uma ilha onde o Verão é permanente, a terra de uma fertilidade mágica e os habitantes gozam de uma perene juventude, nela reinando a fraternidade e a paz. Ilha que se situa no Ocidente e se confunde com o paraíso terreno da mitologia celta, foi várias vezes demandada em navegaçóes que a identificam com a ilha de São Brandão, cujo registo de viagem data, pelo menos, do século IX $^{16}$. A Cucanha assimila o mito da Idade de Ouro nas bondades da terra e, na sua versão mais difundida, é um paraíso dos pobres, onde todos os desejos se tornam realidade. Ecos do mito podem captar-se, entre nós, na Nau de Amores, uma peça de Gil Vicente representada em 1527, onde o Príncipe da Normandia manifesta a vontade de descobrir a ilha encantada:

\author{
"Y, pues todo el trabajar \\ es viento sin la ventura, \\ quiérome aventurar, \\ y matar la desventura \\ por las ondas de la mar. \\ Porque me han dicho, Señora, \\ que la ventura más cierta \\ en una ínsula mora, \\ solitaria, muy desierta,
}

\footnotetext{
${ }^{15}$ Ernst Bloch, The Principle of Hope (Das Prinzip Hoffnung), Cambridge, Massachusetts, 3 vols., 1986.

16 A. L. Morton, The English Utopia, Londres, 1952, pp. 11-34.
} 
hazia do sale el aurora.

Adó hay tantas corrientes

en la mar de que es cercada,

tormentas, inconvenientes,

y tan peligrosa la entrada

que las ondas son serpientes." 17

Para alcançar esta ilha é preciso vencer muitos obstáculos, como as águas revoltas em torno da ilha dos Feácios na Odisseia ou como aqueles que afrontarão os nautas de Camóes. A Ilha dos Amores, criada por Vénus para que eles pudessem «refocilar a lassa humanidade», apresenta muitos dos atributos que caracterizam a terra da Cucanha, mencionada pelo dramaturgo na Farsa dos Almocreves, e vem já adornada de todos os recursos de que carece a ilha vicentina, espaço a ser preenchido pelo fantasma do desejo. Uma natureza amena, um clima permanente de Verão, um solo fértil, árvores carregadas de frutos, um banquete servido com ricos manjares - eis o cenário da ínsula divina onde se dá o consórcio com as ninfas, numa satisfação de todos os desejos como prémio dos perigos sofridos no mar. Só a nível superior, que transcende o horizonte de Cucanha, têm eles a iluminação e compreendem a importância dos seus trabalhos. O quadro pintado por Camóes com cores vivas contrasta no desenho com o traço grosso do pintor Pieter Bruegel na sua ilustração deste tema da Cucanha (1567), onde o enfartamento dos bem-aventurados e a abundância são as notas dominantes.

À mesma matriz do utópico pertence a ambição de um rei eleito, um soberano que ascendesse ao poder não por direito de sangue, nem por leis de sucessão dinástica, senão que pelos seus próprios méritos. Regime político este que, segundo Camóes, vigoraria entre os Chineses:

"Estes o rei que têm não foi nascido

Príncipe, nem dos pais ao filho fica,

Mas elegem aquele que é famoso

Por cavaleiro sábio e virtuoso.” (X.130)

Descrição esta que não reproduz de modo algum a realidade da dinastia Ming. No imaginário português de Quinhentos a China assumia as qualidades de um estado ideal, desenvolvidamente tratado no De Gloria (1549) de D. Jerónimo Osório, como o demonstrou Américo da Costa Ramalho ${ }^{18}$. A ideia da eleição régia, que se louva em Platão e Aristóteles, encontrava no cenário oriental o meio adequado à sua aclimatação. A diferença, que caracteriza o Outro, permite que nele se projecte e materialize o desejo, e os relatos de viajantes que chegavam ao Ocidente acerca da China contribuíam pelo exotismo para a imagem que dela se tinha e que Fernão Mendes Pinto criou menos

17 Gil Vicente, Auto da Barca da Glória, Nao d'amores, Clásicos Casalia, Madrid, 1995, vv. 145-154, p. 108 .

18 A. da Costa Ramalho, Latim renascentista em Portugal (antologia), Coimbra, 1985, pp. 175-176. Cfr. Nair de Nazaré Castro Soares, O Príncipe Ideal no Século XVI e a obra de D. Jerónimo Osório, Coimbra, 1994. 
como utopia do que eutopia - lugar com condiçóes propícias à formação de uma sociedade justa.

A presença da utopia no poema épico pressupóe uma crítica do tempo vivido e evidencia o desejo de um futuro que corresponda à altura da empresa realizada. $\mathrm{O}$ descontentamento e a reflexão crítica expressos no poema, a consciência do conflito ético e o pessimismo do poeta, cansado de falar «a gente surda endurecida» (X.145), encontram sem dúvida no leitor d'Os Lusíadas do nosso tempo uma forte receptividade. Por outro lado, a firmeza das suas convicçóes, o seu Cristianismo militante e o próprio tratamento épico dado à viagem do descobrimento alienam aqueles que se identificam com a revolta da periferia contra a suposta superioridade da cultura europeia, já que a literatura latino-americana, com a sua originalidade, lhe disputa hoje o privilégio em certos domínios. O testemunho do poeta e do homem, do ser que pensa e sente a sua circunstância, esse testemunho convida a uma meditação que prosseguirá certamente para além do fim do século. O imaginário da epopeia e as associaçóes que esta invoca exercerão o seu fascínio sobre o leitor, e Os Lusíadas, como obra-prima que é, continuará a ser lido enquanto houver no mundo quem fale e ame a língua portuguesa. Mas o seu público será o do escol educado, muito provavelmente um público cada vez mais reduzido, se a tendência demótica ou populista, que se afirma com a filosofia do fim do Milénio, conseguir implantar entre nós um relativismo estético, tão dogmático quanto as ortodoxias que pretende combater, um relativismo que vê a obra literária como um produto de consumo, apostado em anular a consagração de que a epopeia até agora tem gozado, graças a um trabalho de escolaridade e de educação que se tem mantido ao longo dos séculos. A Cidade Ideal, miragem perseguida no que se tornou um processo de expiação dos erros pós-imperiais do Ocidente e das suas ideias, continua a furtar-se, no entanto, a aspiraçóes colectivas que se confundem com as brumas da utopia. 